\title{
ON APPROXIMATION PROPERTIES OF SOME CLASS POSITIVE LINEAR OPERATORS IN $q$-ANALYSIS
}

\author{
ERSIN ŞIMŞEK AND TUNCAY TUNÇ
}

\begin{abstract}
This paper is concerned with some sequences of the positive linear operators based on $q$-Calculus. The approximation properties and the rate of convergence of these sequences of $q$-discrete type is established by means of the modulus of continuity. Moreover we give Voronovskaya-type theorems. Finally we present some applications such as $q$-Bernstein operators and $q$-Meyer-König and Zeller operators.
\end{abstract}

Mathematics subject classification (2010): 05A30, 41A25, 41A36, 47B38.

Keywords and phrases: $q$-calculus, generating functions, positive linear operators, rate of convergence.

\section{REFERENCES}

[1] A. ARAL, O. DoĞRU, Bleimann Butzer and Hahn operators based on q-integers, J. Inequal. Appl. 2007, (2007), 12 pp. [Article ID 79410].

[2] A. Altin, O. Dogru, F. TAsdelen, The generalization of Meyer-König and Zeller operators by generating functions, J. Math. Anal. Appl. 312 (2005), 181-194.

[3] A. Aral, V. Gupta, R. P. Agarwal, Applications of q-Calculus in Operator Theory, Springer, New York, 2013.

[4] A. Aral, V. Gupta, On q-Baskakov type operators, Demons. Math. 42, 1 (2009), 109-122.

[5] A. II'Inski, S. Ostrovska, Convergence of generalized Bernstein polynomials, J. Approx. Theor. 116, (2002), 100-112.

[6] A. LuPAŞ, A q-analogue of the Bernstein operator, University of Cluj-Napoca Seminar on numerical and statistical calculus 9, (1987), 85-92.

[7] C. RADU, On statistical approximation of a general class of positive linear operators extended in q-calculus, Appl. Math. Comput. 215, (2009), 2317-2325.

[8] E. Simsek, T. Tunc, On the Construction of $q$-Analogues for some Positive Linear Operators, Filomat, 31:13 (2017), 4287-4295.

[9] F. H. JACKSON, On q-functions and a certain difference operator, Trans. Roy. Soc. Edin. 46, (1908), 253-281.

[10] F. SCHURER, Positive linear operators in approximation theory, Mathematical Institute of the Technological University Delft, Report, 1962.

[11] G. M. PHILLIPS, Bernstein polynomials based on the q-integers, Ann. Numer. Math. 4, (1997), 511518.

[12] G. Nowak, V. Gupta, The Rate of Pointwise Approximation of Positive Linear Operators Based on q-Integer, Ukrainian Math, J. 3, (2011), 350-360.

[13] L. CARLitZ, q-Bernoulli numbers and polynomials, Duke Math. J. 15, 4 (1948), 987-1000.

[14] N. I. Mahmudov, P. SABANCigIL, q-Parametric Bleimann Butzer and Hahn operators, J. Inequal. Appl. 2008, (2008), 15 pp. [Article ID 816367].

[15] O. Agratini, G. NowAK, On a generalization of Bleimann, Butzer and Hahn operators based on q-integers, Math. Comput. Model. 53, 5-6 (2011), 699-706.

[16] O. DoĞRU, O. Duman, Statistical approximation of Meyer-König and Zeller operators based on the q-integers, Publ. Math. Debrecen 68, (2006), 190-214. 
[17] P. M. Rajkovic, M. S. Stankovic, S. D. Marinkovic, Mean value theorems in q-calculus, Math. Vesnic. 54, (2002), 171-178.

[18] T. ERnst, A new notation for q-calculus and a new q-Taylor formula, Uppsala University Report Depert. Math., (1999), 1-28.

[19] T. TRIF, Meyer, König and Zeller operators based on the q-integers, Rev. Anal. Numer. Theor. Approx. 29, (2002), 221-229.

[20] V. A. BASKAKOV, An example of sequence of linear positive operators in the space of continuous functions, Dokl. Akad. Nauk. SSSR 113 (1957), 249-251.

[21] V. KaC, P. Cheung, Quantum Calculus, Universitext Springer, New York, 2002.

[22] V. S. VIDENSKII, On some class of q-parametric positive operators, Operator Theory: Advances and Applications 158, (2005), 213-222.

[23] W. Heping, Properties of convergence for the q-Meyer-König and Zeller operators, J. Math. Anal. Appl. 335, 2 (2007), 1360-1373.

[24] W. HePing, F. Meng, The rate of convergence of $q$-Bernstein polynomials for $0<q<1$, J. Approx. Theor. 136, (2005), 151-158.

[25] Z. FinTA, V. GuPTA, Approximation properties of q-Baskakov operators, Cent. Eur. J. Math. 8, 1 (2009), 199-211.

[26] N. L. Braha, V. LokU, H. M. SRivastava, $\Lambda^{2}$-Weighted statistical convergence and Korovkin and Voronovskaya type theorems, Appl. Math. Comput. 266, (2015), 675-686.

[27] U. KADAK, N. L. BRAHA, H. M. SRIVASTAVA, Statistical weighted $\mathscr{B}$-summability and its applications to approximation theorems, Appl. Math. Comput. 302, (2017), 80-96.

[28] H. M. Srivastava, M. Mursaleen, A. Alotaibi, M. Nasiruzzaman, A. A. H. Al-Abied, Some approximation results involving the q-Szász-Mirakjan-Kantorovich type operators via Dunkl's generalization, Math. Meth. Appl. Sci. 40 doi:10.1002/mma.4397, (2017), 5437-5452.

[29] M. Mursaleen, A. Khan, H. M. SRivastava, K. S. Nis AR, Operators constructed by means of $q$-Lagrange polynomials and A-statistical approximation, Appl. Math. Comput. 219, 12 (2017), 6911-6918.

[30] M. Mursaleen, K. J. Ansari, A. Khan, Approximation by Kantorovich Type q-Bernstein-Stancu Operators, Complex Analysis and Operator Theory. 11, 1 (2017), 85-107.

[31] L. Naim Braha, H. M. SRivastava, S. A. Mohiuddine, A Korovkin's type approximation theorem for periodic functions via the statistical summability of the generalized de la Vallée Poussin mean, Appl. Math. Comput. 228, (2014), 162-169.

[32] V. GuPTA, Some approximation properties of q-Durrmeyer operators, Appl. Math. Comput. 197, 1 (2008), 172-178.

[33] V. Gupta, Z. Finta, On certain q-Durrmeyer type operators, Appl. Math. Comput. 209, (2009), $415-420$.

[34] Ö. DamLaoĞLU, Approximation by Kantorovich type q-Bernstein operators, in Proceedings of the 12th WSEAS International Conference on Applied Mathematics, Cairo, Egypt, (2007), 113-117.

[35] V. Gupta, C. Radu, Statistical approximation properties of q-Baskakov Kantorovich operators, Cent. Eur. J. Math. 7 (4), (2009), 809-818. 